\title{
Europe sets hopes on twin eyes in the sky
}

Paris. Scientists across the world will be keeping their fingers crossed tomorrow night (21 April) when ERS-2, the European Space Agency (ESA)'s latest remote-sensing satellite, takes its place in orbit alongside its ageing predecessor, ERS-1.

Any accident or delay in the launch of the second satellite would spoil a unique opportunity to carry out new research that is only possible using both satellites in tandem.

ERS-2 was originally designed merely to take over the baton from ERS-1, which was launched in 1991. But at the end of 1993, when it became clear that ERS-1 was likely to be able to continue operating beyond its 30 -month design life, users asked the space agency to consider operating both satellites in tandem (see Nature 370, 317; 1994). The extra costs were formally approved by the ESA council last month.

Like ERS-1, ERS-2 is equipped with a radar altimeter, which gives precise measurements of the heights of the oceans and ice sheets, and a synthetic aperture radar (SAR), which provides images with a resolution of 10 centimetres.

The tandem mission will allow full exploitation of the SAR's unique ability to carry out interferometry - the comparison of two pictures of the same area taken at different times - and will also provide a precise digital three-dimensional map of the Earth's land surfaces.

But to place ERS-2 in the appropriate orbit, Arianespace has just a four-minute window to launch the satellite, to be carried on an Ariane IV launcher from ESA's space centre in Kourou, French Guiana.
Moreover, following launch failures in January and December last year, Arianespace now has a backlog of 38 launches. If the launch of ERS-2 is postponed, it may be

\section{IMAGE UNAVAILABLE FOR COPYRIGHT REASONS}

ERS-2's GOME will measure atmospheric ozone in blocks of $\mathbf{4 0}$ by $\mathbf{8 0}$ kilometres.

difficult for the company to find it another slot in its planned hectic schedule of one launch every three weeks.

Apart from assuring the continuity of the ERS programme and working in tandem with its predecessor ERS-1, ERS-2 will have an additional three channels in its scanning radiometer, allowing it to track changes in vegetation cover in great detail.

The satellite will also carry a new instrument to measure the atmosphere's ozone content. GOME (Global Ozone Monitoring Instrument) as it is known, marks a major advance on existing US and Russian satellite-borne ozone-measuring instruments.
GOME, in particular, possesses a broader spectral range $(240-790 \mathrm{~nm})$, than existing instruments, which work only in the ultraviolet (UV). This will allow it to take measurements in the polar regions in late winter, when the Sun is too low for ultraviolet light.

Compensating for this blind spot in existing instruments at present, requires the release every year of stratospheric balloons over Northern Europe. These balloons give only a part of the overall ozone picture. GOME should provide ozone maps of the entire globe every three days.

ESA officials are being cautious, however, about overselling GOME's potential, given the instrument was hurriedly built in only five years - complete validation of the instrument would have taken ten years of development and testing. "We cannot give a 100 per cent guarantee that GOME will live up to its expectations", one official says.

The remote-sensing satellite programme is widely regarded as one of ESA's most successful science missions. The number of users of ERS-1 data is growing at 25 to 30 per cent annually, and the space agency has received more than 15,000 requests for data. More than half the data go free of charge to 270 selected research teams; seven per cent of the data is bought by commercial users at list price.

By reusing technologies developed for ERS-1, ESA has been able to build ERS-2 for ECU550 million (US\$714 million), 60 per cent of the cost of ERS-1. The new satellite will operate from 1995 to 1998, when it will be replaced by Envisat. Declan Butler

\section{Patent convention 'needs new protocol on moral issues'}

London. A new protocol should be drafted to the European Patent Convention, setting out in detail how its clause specifying when patents cannot be granted on moral terms should be interpreted, according to a toplevel British bioethics advisory committee.

In a report to be published this week on the ethical and legal issues raised by the use of human tissue in medical treatment and research, the Nuffield Council on Bioethics - widely seen as the United Kingdom's national bioethics council - urges the government to press its co-signatories of the convention to negotiate such a protocol to clear up current confusion over the clause.

The report also suggests changes in legislation in order that, under strict safeguards, tissue can be removed for non-therapeutic research purposes from 'incompetent adults' - for example, those suffering from Alzheimer's disease - who may be incapable of fulfilling current requirements for providing informed consent.

The report has been prepared by a work- ing party consisting of medical, ethical and legal experts. It was chaired by Dame Rosalinde Hurley, professor of microbiology at the Royal Postgraduate Medical School.

Citing the recent dispute between the University of California and a patient, John Moore, over the ownership of cell lines taken during routine medical procedures and subsequently used in a commercial procedure, Sir Patrick Nairne, the chairman of the council, says that the uses of human tissue in both therapy and research are presenting "more, and more difficult, problems of ethics and law."

On the question of patents, the report says that a body of opinion would like clarification of the EPC clause that excludes patents that contravene "public order or morality". Given the European Parliament has recently rejected attempts by the European Commission to draft a directive aimed at achieving this goal (see Nature 374, 103; 1995), the report says that "the preferred course may be an amendment to or clarifica- tion of the EPC itself."

"It might be helpful if governments could agree on some concepts which might guide national courts in deciding these issues," says Hurley. She adds that the working party was less enthusiastic about other possible courses of action - - such as the creation of a Europe-wide ethics committee concerned exclusively with the resolution of ethical issues in patent applications.

As far as issues involving informed consent are concerned, the working party says that - in order to avoid the type of dilemma raised by the John Moore case in the United States - the law should proceed on any claim over removed tissue by looking closely at the basis of the consent that was given to the removal procedure.

"In particular, it should be regarded as entailed in consent to medical treatment that tissue removed in the course of treatment will be regarded as having been abandoned by the person from whom it was removed," says the working party. 